\title{
DISPONIBILIDADE DE NUTRIENTES E CRESCIMENTO DE PORTA-ENXERTOS DE CITROS FERTILIZADOS COM FERTILIZANTES CONVENCIONAIS E DE LIBERAÇÃO LENTA ${ }^{1}$
}

\author{
LUCIANA VENTUROTTI BRAUN DE ALMEIDA ${ }^{2}$, CLÁUDIA SALES MARINHO ${ }^{3 *}$, \\ RODRIGO DE ALMEIDA MUNIZ ${ }^{4}$, ALMY JÚNIOR CORDEIRO DE CARVALHO ${ }^{3}$
}

RESUMO - Os fertilizantes de liberação lenta são usados para reduzir a frequência das adubações por disponibilizar gradualmente os nutrientes às plantas. Entretanto, a liberação de nutrientes deve coincidir com a demanda nutricional das plantas. O objetivo deste trabalho foi avaliar a disponibilidade de $\mathrm{N}$, P e K e o crescimento de dois porta-enxertos de citros quando fertilizados com fertilizantes de liberação lenta e fertilizantes convencionais. Foram avaliados dois manejos de adubação em substrato comercial (com fertilizantes de liberação lenta e somente com fertilizantes convencionais), dois porta-enxertos (limoeiro 'Cravo' e tangerineira 'Sunki') e cinco épocas de avaliação (30; 60; 90; 120 e 180 dias após o replantio das mudas), com cinco repetições e duas plantas por parcela. $\mathrm{O}$ emprego do fertilizante de liberação lenta aumentou o diâmetro de caule, número de folhas, teores de $\mathrm{P}$ nas folhas e disponibilidade de $\mathrm{P}$ e $\mathrm{K}$ no substrato, quando comparado ao emprego da fertilização convencional.

Termos para indexação: Citrus limonia, Citrus sunki, produção de mudas, adubação.

\section{NUTRIENT AVAILABILITY AND GROWTH OF CITRUS ROOTSTOCK FERTILIZED WITH CONVENTIONAL AND SLOW RELEASE FERTILIZERS}

\begin{abstract}
The slow release fertilizers are used to reduce the frequency of fertilization because provides gradually the nutrients to the plants. However the release of nutrients should be the same that nutrient demand by plants. The aim of this study was to evaluate availability of N, P and K and growth of two citrus rootstocks when slow release and conventional fertilizers were applied. Two fertilizations systems in a commercial substrate were appraised (with controlled-release fertilizer and with only conventional fertilizers), two rootstock ('Rangpur lime' tree and tangerine 'Sunki' tree) and five sampling times (30, 60, 90, 120 and 180 days after the transplanting) with five repetitions and two plants per plot. The uses of slow release fertilizer increase stem diameter, leaves number, $\mathrm{P}$ contents in leaves of rootstocks and $\mathrm{P}$ and $\mathrm{K}$ disponibility in substrate, when compared with use of conventional fertilization.
\end{abstract}

Index terms: Citrus limonia, Citrus sunki, nursery trees production, fertilization.

\section{INTRODUÇÃO}

O parcelamento das adubações em cobertura, via aplicação manual ou via fertirrigação, tem sido utilizado na produção da muda cítrica a fim de minimizar as perdas por lixiviação de nutrientes, atender à demanda nutricional durante o seu período de crescimento, promovendo o desenvolvimento adequado das plantas (MATTOS JR. et al., 2010; PRADO et al., 2008).

Os fertilizantes de liberação lenta também podem ser usados na produção de porta-enxertos de citros (SERRANO et al., 2006) com o objetivo de reduzir os parcelamentos e, ao mesmo tempo, disponibilizar gradualmente os nutrientes a essas mudas.

Nos fertilizantes de liberação lenta, a existência de uma resina orgânica ao redor dos grânulos controla a saída dos nutrientes para o meio. Após a adubação, a umidade penetra na resina que envolve o fertilizante, solubilizando os nutrientes em seu interior. Em função da diferença de concentração entre a solução do meio e a do interior dos grânulos, os nutrientes vão sendo liberados de forma gradual. Essa liberação é diretamente proporcional à tempe-

\footnotetext{
(Trabalho 046-11). Recebido em: 06-06-2011. Aceito para publicação em: 05-12-2011. Parte da tese do primeiro autor apresentada à Universidade Estadual do Norte Fluminense Darcy Ribeiro para a obtenção do título de mestre em Produção Vegetal.

${ }^{2}$ Engenheiro Agrônomo, Mestre, UENF/CCTA/LFIT. E-mail: lbraun@uenf.br

${ }^{3}$ Professor Associado UENF/CCTA/LFIT - Av. Alberto Lamego, 2000, Horto. Cep: 28013600 - Campos dos Goytacazes - RJ - Brasil. *autor correspondente: E-mail: marinho@uenf.br

${ }^{4}$ Aluno do curso de graduação em Agronomia - UENF/CCTA/LFIT.
} 
ratura e à umidade do substrato, sendo mais rápida na medida em que temperatura e umidade se elevam (SGARBI et al., 1999).

Mudas de café e de eucalipto fertilizadas com adubo de liberação lenta tiveram maior produção de biomassa aérea e radicular em relação às adubadas com fertilizantes convencionais (ANDRADE NETO et al., 1999; SGARBI et al., 1999). Mendonça et al. (2008) recomendam um fertilizante de liberação lenta para a formação de mudas de tamarindeiro. Por outro lado, não foram observadas diferenças no crescimento da laranjeira 'Valência' no primeiro ano de plantio, quando esta foi submetida à adubação nitrogenada via fertilizantes solúveis ou via fertilizantes de liberação lenta (GIRARDI; MOURÃO FILHO, 2004).

O presente trabalho foi conduzido com a finalidade de fornecer subsídios para a decisão entre o emprego de fertilizantes de adubação lenta ou convencionais na adubação de porta-enxertos de citros.

O trabalho teve como objetivos a avaliação do crescimento e a disponibilidade de nutrientes para dois porta-enxertos de citros fertilizados com fertilizante de liberação lenta e com fertilizantes convencionais, em fase posterior ao transplante de tubetes para vasos.

\section{MATERIAL E MÉTODOS}

O trabalho foi conduzido em viveiro telado, localizado na área experimental da Universidade Estadual do Norte Fluminense Darcy Ribeiro, localizada no município de Campos dos Goytacazes, no período de dezembro de 2002 a agosto de 2003, na fase após transplante dos tubetes para vasos. A temperatura máxima média registrada dentro do viveiro, no período do experimento, foi de $32,2{ }^{\circ} \mathrm{C}$, e a mínima média foi de $22,8^{\circ} \mathrm{C}$.

O experimento foi instalado sob delineamento experimental em blocos casualizados, em esquema fatorial $2 \times 2 \times 5$, no qual foram avaliados dois sistemas de adubação (com fertilizante de liberação lenta e apenas com fertilizantes convencionais), dois portaenxertos (limoeiro 'Cravo' e tangerineira 'Sunki') e cinco épocas de amostragem (30; 60; 90; 120 e 180 dias após o transplante), com cinco repetições e duas plantas por parcela.

Foi utilizado um substrato comercial à base de casca de pínus. As sementes dos porta-enxertos foram obtidas de plantas matrizes do Centro APTA Citros Sylvio Moreira - IAC-Cordeirópolis-SP. A semeadura foi realizada em tubetes com capacidade para $50 \mathrm{~cm}^{3}$, em bandejas com capacidade para 96 tubetes. O substrato para preenchimento dos tubetes recebeu fertilizante de liberação lenta, marca Osmo- cote, na formulação 14-14-14, na dosagem de 3.000 $\mathrm{g}$ por $\mathrm{m}^{3}$ de substrato.

As bandejas com os tubetes ficaram sobre bancadas compostas por fios de arame esticados a $1 \mathrm{~m}$ do solo. Após a emergência, foram realizados desbastes para a eliminação de plantas atípicas e de menor porte, deixando-se uma planta por tubete. Quando atingiram entre 10 e $15 \mathrm{~cm}$ de altura, foi efetuada nova seleção dos porta-enxertos, e estes foram transferidos para vasos de plástico rígido cônicos com volume de $3,8 \mathrm{dm}^{3}$.

O substrato para preenchimento dos vasos recebeu adubação de acordo com os tratamentos. A adubação aplicada baseou-se nos resultados de pesquisa de Serrano et al. (2006), que estudou diferentes doses de adubo de liberação lenta para esse tipo de substrato. Nos dois sistemas de adubação, foram aplicadas as mesmas quantidades de nutrientes, sendo variadas as fontes dos nutrientes e o parcelamento das aplicações. As quantidades aplicadas foram de $1.122 \mathrm{~g} \mathrm{~m}^{-3}$ de N, $822 \mathrm{~g} \mathrm{~m}^{-3}$ de $\mathrm{P}_{2} \mathrm{O}_{5}$ e $792 \mathrm{~g} \mathrm{~m}^{-3} \mathrm{de}$ $\mathrm{K}_{2} \mathrm{O}$. No sistema no qual foi empregado o fertilizante de liberação lenta, foram aplicados $6.600 \mathrm{~g}$ do fertilizante marca Osmocote, fórmula 17-07-12, com liberação entre 8 e 9 meses, à temperatura de $26,7^{\circ} \mathrm{C}$ (especificações do fabricante), mais $2 \mathrm{~kg}$ de superfosfato simples por metro cúbico de substrato. Os dois fertilizantes foram misturados e homogeneizados ao substrato, criteriosamente, antes do preenchimento dos vasos. No sistema de adubação convencional, foram aplicados por metro cúbico de substrato: $4.567 \mathrm{~g}$ de superfosfato simples misturado ao substrato e homogeneizado, antes do enchimento dos vasos e, posteriormente, em cobertura, $1.760 \mathrm{~g}$ de $\mathrm{KNO}_{3}$ e $1.960 \mathrm{~g}$ de ureia $\left(6,67 \mathrm{~g}\right.$ de $\mathrm{KNO}_{3}$ e 7,44 $\mathrm{g}$ de ureia por vaso de $3,8 \mathrm{dm}^{3}$ ), sendo estes últimos parcelados em 5 aplicações, com início aos 20 dias após o transplante e com reaplicações a cada 30 dias.

Como adubação complementar e fonte de micronutrientes, as plantas receberam adubação foliar, baseada nas recomendações de Boareto et al. (1999), com algumas adaptações. Foram aplicados, quinzenalmente: $5,0 \mathrm{~g} \mathrm{~L}^{-1}$ de ureia, $3,5 \mathrm{~g} \mathrm{~L}^{-1}$ de sulfato de zinco, 2,5 $\mathrm{g} \mathrm{L}^{-1}$ de sulfato de manganês, $1,0 \mathrm{~g} \mathrm{~L}^{-1}$ de ácido bórico, 2,0 $\mathrm{g} \mathrm{L}^{-1}$ de cloreto de potássio, 1,0 $\mathrm{g} \mathrm{L}^{-1}$ de oxicloreto de cobre, 5,0 $\mathrm{g} \mathrm{L}^{-1}$ de sulfato de magnésio e $0,5 \mathrm{~g} \mathrm{~L}^{-1}$ de sulfato ferroso. Aos 60 dias após a semeadura, foram realizadas pulverizações com cloreto de cálcio $\left(1 \mathrm{~g} \mathrm{~L}^{-1}\right)$ e que prosseguiram a cada quinze dias.

Dos 30 aos 180 dias após o transplante, foi feita análise do substrato contido no vaso. Os portaenxertos, nessas ocasiões, foram avaliados quanto à altura, diâmetro de caule na altura do colo e número 
de folhas.

Nas épocas das amostragens, as folhas foram destacadas, limpas com algodão embebido em água deionizada, acondicionadas em sacos de papel e levadas à estufa com circulação forçada de ar, à temperatura de $72^{\circ} \mathrm{C}$, durante 48 horas. Após a secagem, as folhas foram trituradas em moinho tipo Wiley, com peneira de 20 mesh, e armazenadas em frascos hermeticamente fechados. Posteriormente, foram realizadas as análises para a determinação dos teores de N, P e K. O N foi determinado pelo método de Nessler, após digestão sulfúrica da matéria seca. Os demais nutrientes foram determinados em extrato da digestão nítrico-perclórica, sendo o P quantificado colorimetricamente pelo método do molibdato, e o K por espectrometria de emissão de chama, conforme metodologias descritas por Malavolta et al. (1997).

O substrato contido em cada vaso foi colocado sobre um filme plástico e homogeneizado. Foi retirada, então, uma amostra úmida que foi macerada em almofariz e utilizada para a determinação dos teores de $\mathrm{N}$ pelo método de Nessler, após digestão sulfúrica, conforme metodologia descrita por Malavolta et al. (1997). Uma segunda amostra foi pesada $(100 \mathrm{~g})$ e levada à estufa de secagem com circulação forçada de ar, à temperatura de $60^{\circ} \mathrm{C}$, por 48 horas, para determinar o teor de umidade do substrato. Uma terceira amostra desse substrato, de aproximadamente $80 \mathrm{~g}$, foi colocada para secar à sombra, em temperatura ambiente $\left(25\right.$ a $\left.30^{\circ} \mathrm{C}\right)$, durante 72 horas. Desta amostra, os grânulos foram extraídos manualmente do fertilizante de liberação lenta, e o restante do substrato foi peneirado em peneira de malha de dois mesh e, posteriormente, foram determinados os teores de $\mathrm{Pe}$ $\mathrm{K}$ disponíveis de acordo com a metodologia descrita por Silva (1999).

Os dados foram submetidos às análises de variância. Para porta-enxertos e tipos de manejo da adubação, as médias foram comparadas pelo teste de Tukey, a 5\% de probabilidade, enquanto as médias de cada época de amostragem foram submetidas a análises de regressão.

\section{RESULTADOS E DISCUSSÃO}

As curvas de crescimento para os dois portaenxertos em função dos tratamentos são apresentadas na Figura 1. O fertilizante de liberação lenta - FLL proporcionou maior crescimento em diâmetro de caule e número de folhas para os dois porta-enxertos com diferenças significativas nas médias obtidas aos 180 dias após o transplante (Tabela 1). Entretanto, as diferenças entre as médias de altura não foram signi- ficativas na avaliação efetuada aos 180 dias, para os porta-enxertos sob os dois tipos de fertilização.

Independentemente do tipo de adubação utilizada, as médias de altura e diâmetro de caule do limoeiro 'Cravo' foram superiores às obtidas para a tangerineira 'Sunki'. Em relação ao número de folhas, as médias obtidas foram semelhantes para os dois porta-enxertos (Tabela 1). O maior vigor do limoeiro 'Cravo' em relação à tangerineira 'Sunki' foi observado, também, por Reyes e Ruiz (1984).

A maior concentração de $\mathrm{N}$ foi observada na primeira amostragem, posteriormente com tendência de queda, para os dois manejos de adubação (Figura 2). Os maiores teores iniciais de N, observados no substrato fertilizado com FLL, eram esperados, uma vez que nesse manejo de adubação a quantidade total de fertilizante foi adicionada ao substrato antes do transplante, enquanto no manejo com fertilizantes convencionais - FC a adubação foi parcelada.

A disponibilidade de $\mathrm{P}$ apresentou-se mais uniforme ao longo das amostragens no substrato fertilizado com FLL (curvas com menores inclinações). Os maiores teores disponíveis de $\mathrm{P}$ foram observados também no substrato fertilizado com FLL (Figura 2). A quantidade de P aplicada na forma do FLL, em adição ao superfosfato simples, resultou em maior disponibilidade de $\mathrm{P}$.

Tanto o $\mathrm{N}$ quanto o $\mathrm{P}$ são dois nutrientes cujo aumento na disponibilidade relaciona com maior crescimento de mudas cítricas, conforme observado por Scivittaro et al. (2004) e Rezende et al. (1995), respectivamente. A adubação com N, P e K proporciona acúmulo de maiores quantidades desses nutrientes na parte aérea e raízes de mudas de laranjeira (PRADO et al., 2009; PRADO et al., 2008).

Os teores de $\mathrm{N}$ nas folhas da tangerineira 'Sunki' não diferiram entre os manejos de adubação empregados, enquanto para o 'Cravo' esses teores apresentaram-se inicialmente mais altos na fertilização com o FLL (Figura 3).

Neste trabalho, o maior crescimento em diâmetro e em número de folhas dos porta-enxertos fertilizados com o FLL, foi acompanhado pela maior disponibilidade de P no substrato de cultivo (Figura 2), durante todo o período de crescimento, e por maiores teores deste nutriente nas folhas dos dois porta-enxertos, nas duas últimas épocas de avaliação (Figura 3).

Rezende et al. (1995) verificaram que, em média, as plantas de limoeiro 'Cravo' que receberam maior dose de superfosfato simples, em diferentes volumes de substrato, atingiram o ponto de enxertia (definido pelo diâmetro de caule) em tempo menor, e os maiores valores de altura e diâmetro foram 
proporcionados pelo maior volume de substrato e pela maior dose de superfosfato simples aplicada, equivalente a $5.120 \mathrm{~g}$ de $\mathrm{P}_{2} \mathrm{O}_{5}$ por metro cúbico de substrato. No presente trabalho, não foi verificado maior crescimento em altura, entretanto o maior diâmetro do caule em plantas cultivadas com o FLL, permitiria a realização da enxertia em menor tempo.

Os teores de $\mathrm{K}$ disponíveis apresentaram-se inicialmente mais altos no substrato fertilizado com o FLL, para os dois porta-enxertos, com tendência de se igualar aos 180 dias quando o porta-enxerto cultivado foi o 'Cravo' (Figura 2).

Nas primeiras avaliações, foram verificados maiores teores de $\mathrm{K}$ nas folhas dos porta-enxertos fertilizados com o FLL, porém, após os 60 dias, os teores mais altos foram verificados nas folhas dos porta-enxertos fertilizados com o FC (Figura 3). O maior crescimento em diâmetro e número de folhas das plantas adubadas com fertilizante de liberação lenta se deve, provavelmente, à liberação gradual dos nutrientes (TOMASZEWKA et al., 2002). É interessante observar que os fertilizantes de liberação lenta são utilizados com a justificativa de evitar maiores perdas, principalmente de $\mathrm{N}$ e $\mathrm{K}$, por lixiviação. No caso do $\mathrm{P}$, nutriente de menor mobilidade no solo (substrato), a maior disponibilidade pode estar relacionada a outros mecanismos como menor adsorção pelas partículas do substrato. Neste experimento, apenas uma parte do $\mathrm{P}$ foi fornecida na forma do FLL, e este percentual contribuiu para maior disponibilidade de $\mathrm{P}$ observada durante todas as épocas avaliadas. Esses dados sugerem que o uso de fertilizantes de liberação lenta contendo P em sua formulação pode permitir a redução da quantidade de $\mathrm{P}$ a ser suplementada por fontes convencionais.

No caso deste experimento, o uso do FLL na produção de porta-enxerto cítrico justificou-se em função do crescimento mais rápido, melhoria do estado nutricional e redução das atividades operacionais no viveiro.

TABELA 1- Médias aos 180 dias após o trasplante para altura, diâmetro do caule e número de folhas dos porta-enxertos 'Cravo'e 'Sunki', em função do tipo de fertlização, convencional ou de liberação lenta.

\begin{tabular}{c|c|c|c|c}
\hline Tipo de fertilização & Porta-enxerto & Liberação lenta & Convencional & Média \\
\hline \multirow{3}{*}{ Altura (cm) } & 'Cravo' & 149,20 & 143,35 & $\mathbf{1 4 6 , 2 8 ~ A}$ \\
& 'Sunki' & 105,88 & 106,75 & $\mathbf{1 0 6 , 3 1 ~ B}$ \\
& Média & $\mathbf{1 2 7 , 5 4} \mathbf{a}$ & $\mathbf{1 2 5 , 0 5} \mathbf{~ a}$ & \\
\hline \multirow{3}{*}{ Diâmetro (cm) } & 'Cravo' & 8,65 & 8,01 & $\mathbf{8 , 3 3} \mathbf{A}$ \\
& 'Sunki' & 6,29 & 5,58 & $\mathbf{5 , 9 3} \mathbf{B}$ \\
& Média & $\mathbf{7 , 4 7} \mathbf{a}$ & $\mathbf{6 , 7 9} \mathbf{~ b}$ & \\
\hline \multirow{3}{*}{ Número de folhas } & 'Cravo' & 70,13 & 65,96 & $\mathbf{6 8 , 0 4} \mathbf{A}$ \\
& 'Sunki' & 68,00 & 60,38 & $\mathbf{6 4 , 1 9} \mathbf{A}$ \\
& Média & $\mathbf{6 9 , 0 6} \mathbf{a}$ & $\mathbf{6 3 , 1 7} \mathbf{~ b}$ & \\
\hline
\end{tabular}

Para cada característica, médias seguidas por mesma letra minúscula na linha e maiúscula na coluna não diferem significativamente, pelo teste de Tukey (5\%). 

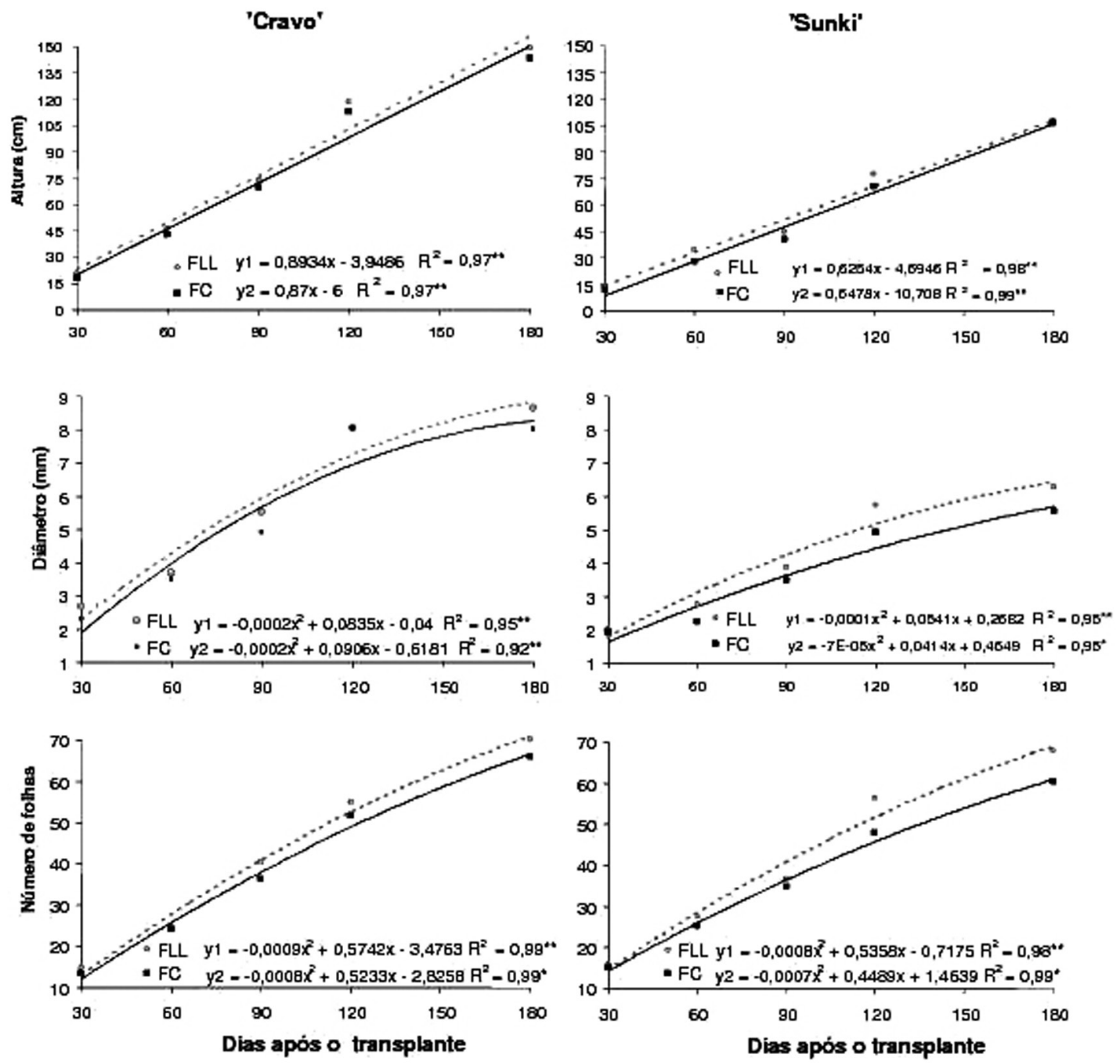

FIGURA 1 - Diâmetro na altura do colo, altura e número de folhas dos porta-enxertos 'Cravo' e 'Sunki', nas várias épocas de amostragem, em função da fertilização com fertilizante de liberação lenta (FLL) ou com fertilizantes convencionais (FC). 

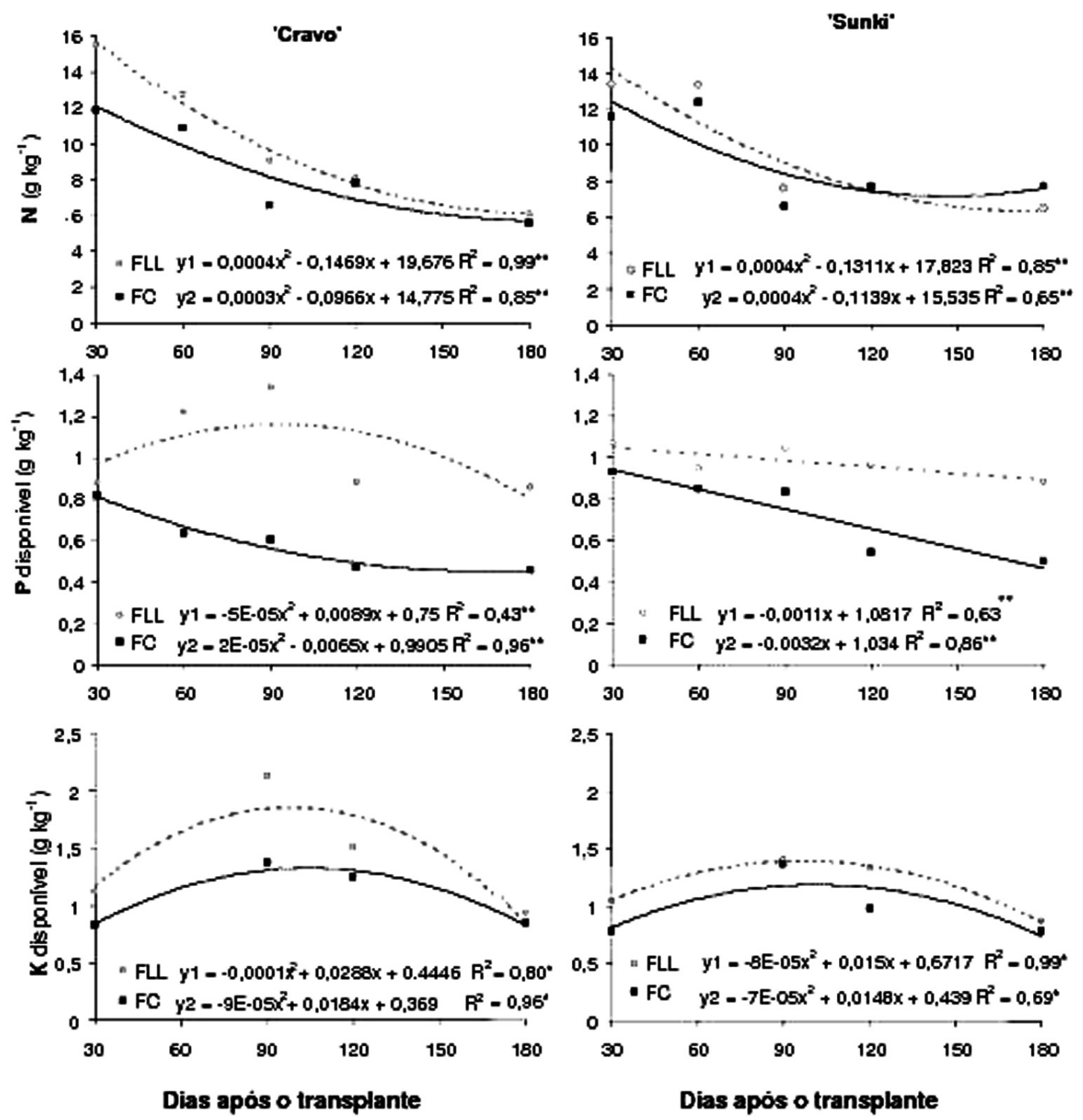

FIURA 2 - Teores de $\mathrm{N}$ e disponibilidade de P e K no substrato de cultivo dos porta-enxertos 'Cravo' e 'Sunki', nas várias épocas de amostragem, em função da fertilização com fertilizante de liberação lenta (FLL) ou com fertilizantes convencionais (FC). 
'Crayo'
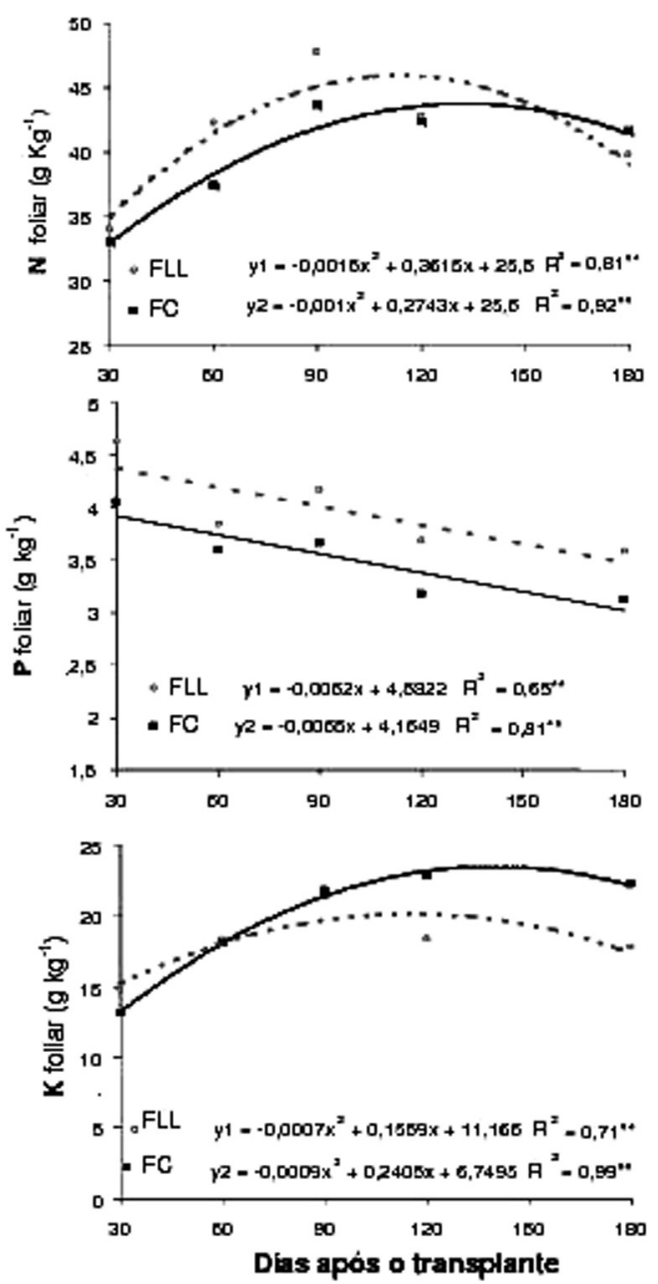

'Sunki'
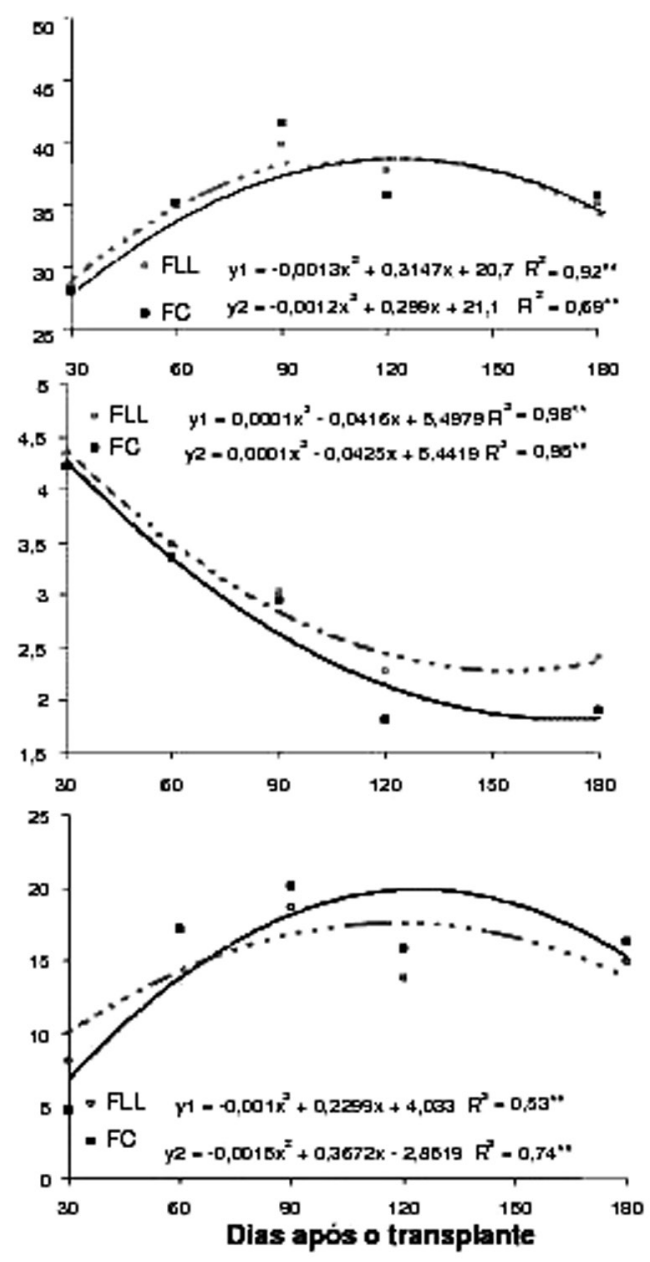

FIGURA 3 - Teores de N, P e K nas folhas dos porta-enxertos 'Cravo' e 'Sunki', nas várias épocas de amostragem, em função da fertilização com fertilizante de liberação lenta (FLL) ou com fertilizantes convencionais (FC). 


\section{CONCLUSÃO}

O emprego do fertilizante de liberação lenta, quando comparado ao fertilizante convencional, resultou em crescimento mais rápido do diâmetro do caule e do número de folhas dos porta-enxertos limoeiro 'Cravo' e tangerineira 'Sunki' e proporcionou maiores teores médios de $\mathrm{P}$ nas folhas, assim como maior disponibilidade de $\mathrm{P}$ e K no substrato.

\section{AGRADECIMENTO}

Ao Centro APTA Citros Sylvio Moreira IAC, pela doação das sementes.

\section{REFERÊNCIAS}

ANDRADE NETO, A. de; MENDES, A. N. G.; GUIMARÃES, P. T. G. Avaliação de substratos alternativos e tipos de adubação para a produção de mudas de cafeeiro (Coffea Arabica 1.) em tubetes. Ciência e Agrotecnologia, Lavras, v. 23, p.270-280, 1999.

BOARETTO, A. E.; MURAOKA, T.; OLIVEIRA, M. W. Adubação foliar corretiva e preventiva em citros. Revista Laranja, Cordeirópolis, v. 20, n. 1, p. 233-250, 1999.

GIRARDI, E. A.; MOURÃO FILHO, F. A. A. Crescimento inicial de laranjeira 'Valência' sobre dois porta-enxertos em função da adubação nitrogenada no plantio. Revista Brasileira de Fruticultura, Jaboticabal, v. 26, n. 1, p. 117-119, 2004.

MALAVOLTA, E.; VITTI, G. C.; OLIVEIRA, S. A. de. Avaliação do estado nutricional das plantas: princípios e aplicações. 2.ed. Piracicaba: POTAFÓS, 1997. $319 \mathrm{p}$.

MATTOS JR., D.; RAMOS, U. M.; QUAGGIO, J. A.; FURLANI, P. R. Nitrogênio e cobre na produção de mudas de citros em diferentes porta-enxertos. Bragantia, Campinas, v. 69, n. 1, p. 135-147, 2010.

MENDONÇA, V.; ABREU, N. A. A. de; SOUZA, H. A. de; TEIXEIRA, G. A.; HAFLE, O. M.; RAMOS, J. D. Diferentes ambientes e Osmocote ${ }^{\circledR}$ na produção de mudas de tamarindeiro (Tamarindus indica). Ciência e Agrotecnologia, Lavras, v. 32, n. 2, p. 391-397, 2008.
PRADO, R. de M.; ROZANE, E.; CAMAROTTI, G. S.; CORREIA, M. A. R.; NATALE, W.; BARBOSA, J. C.; BEUTLER, A. N. Nitrogênio, fósforo e potássio na nutrição e na produção de mudas de laranjeira 'Valência', enxertada sobre citrumeleiro 'Swingle'. Revista Brasileira de Fruticultura, Jaboticabal, v. 30, n. 3, p. 812-817, 2008.

PRADO, R. de M.; ROZANE, E.; CAMAROTTI, G. S.; CORREIA, M. A. R.; NATALE, W.; BARBOSA, J. C. Nitrogênio, fósforo e potássio na nutrição e no crescimento de mudas de laranjeira valência, enxertadas sobre limoeiro cravo. Ciência e Agrotecnologia, Lavras, v. 33, n. 6, p. 1560-1568, 2009.

REZENDE, L. P.; AMARAL, A. M.; CARVALHO, S. A., SOUZA, M. Volume de substrato e superfosfato simples na formação do limoeiro 'Cravo'em vasos. I - Efeitos no crescimento vegetativo. Revista Laranja, Cordeirópolis, v. 16, n. 2, p. 165-177, 1995.

REYES, F. J.; RUÍZ, J. R. Comportamiento en vivero de patrones cítricos tolerantes a Tristeza. Agronomía Tropical, Maracaibo, v. 34 n. 4, p. 35-41, 1984.

SERRANO, L. A. L.; MARINHO, C. S.; BARROSO, D. G.; CARVALHO, A. J. C. Sistema de blocos prensados e doses de adubo de liberação lenta na formação de porta-enxerto cítrico. Ciência Rural, Santa Maria, v. 36, n. 2, p. 441-447, 2006.

SGARBI, F.; SILVEIRA, R. L. V. A.; HIGASHI, E. N.; ANDRADE E PAULA, T.; MOREIRA, A.; RIBEIRO, F. A. Influência da aplicação de fertilizante de liberação controlada na produção de mudas de um clone de Eucalyptus urophylla. In: SIMPÓSIO SOBRE FERTILIZAÇÃO E NUTRIÇÃO FLORESTAL, 1999, Piracicaba. Anais... Piracicaba: IPEF, 1999. $4 \mathrm{p}$.

SILVA, F. C. (Org.). Manual de análises químicas de solos, plantas e fertilizantes. Brasília: Embrapa, 1999. $370 \mathrm{p}$.

SCIVITTARO, W. B.; OLIVEIRA, R. P. de; MORALES, C. F. G.; RADMANN, E. B. Adubação nitrogenada na formação de porta-enxertos de limoeiro 'Cravo' em tubetes. Revista Brasileira de Fruticultura, Jaboticabal , v. 26, n. 1, p. 131 - 135, 2004.

TOMASZEWSKA, M.; JARPSOEWICZ, A. ; KARAKKULSKI, K. Physical and chemical characteristics of polymer coatings in CRF formulation. Desalination, Pulaskiego, v. 146, p. 319-323, 2002. 